\title{
Modeling and Simulation of the Shape Error in the ECM Process
}

\author{
K. P. Rajurkar*, M. S. Hewidy"*,W. H. Liu*, J. Kozak ***, and B. Wei * \\ *Nontraditional Manufacturing Research Center \\ Industrial and Management Systems Engineering Department \\ University of Nebraska-Lincoln, Lincoln, NE 68588 \\ ** Visiting from Menoufia University, Egypt \\ *** Visiting from Warsaw university of Technology, Poland
}

\begin{abstract}
Accuracy in ECM is still a problem that restricts the application of this technology for accurate applications. The present investigation submits a theoretical and experimental study about shape error in the ECM process which has not been attempted before.. Feed rate, applied voltage, electrolyte conductivity and initial gap size have been considered the main factors affecting the shape error value (sometimes reached $40 \mu \mathrm{m}$ for a $40 \mathrm{~mm}$ workpiece length). Experimental results have been found to agree with the estimated values with a difference less than $0.01 \mathrm{~mm}$. The present results emphasize the importance of the consideration of the shape error factor for accurate tool design and shape prediction
\end{abstract}

\section{Introduction}

Metal removal in the ECM process takes place when a voltage is applied between two metal electrodes that are immersed in an electrolyte. "Ions," electrically charged groups of atoms, migrate physically through the electrolyte and in doing so carry the current. The transfer of electrons between the ions and electrodes completes the electrical circuit which allows the workpiece to be dissolved.[1-2].

The process was developed primarily to machine advanced aerospace materials for complex shapes. Currently, ECM is used in areas such as aerospace, automotive, nuclear, surgical implant components, computer parts, forging dies, etc., for fast production with high quality surface and burr free [3].

Manuscript received from Dr: M.S. Hewidy at: 1/ 4/1998, accepted at: 12/ 5/1998,

Engineering research bulletin, Vol. 21, No. 2, 1998, Menoufiya University, Faculty of Engineering, Shehin El- Kom, Egypt, ISSN. 1110-1180. 
The accuracy of the ECM process should be considered from several views: compliance of the finished part with its drawing in terms of shape and dimensions; transfer of tool shape to the workpiece; and repeatability dimensions in parts taken from a sufficiently large lot machined with the same electrode tool. In electrochemical die sinking the primary objective is to maintain the form tolerance as closely as practicable. To achieve this, it is essential to use a tool of the right form and size and the right process parameters. This requires the design of a suitable tool and, in consequence, the computation of the form and dimensions of the finished part that will be produced by a given tool. All of this can be done only from an analysis of ECM accuracy, in other words, it is important to know how machining accuracy is affected by differences in the actual profile of the tool from the design one and in the process parameters from those for which the tool has been designed [4].

An accurate design of the electrode tool in many cases cannot be done for lack of knowledge about some quantitative aspects of the events occurring in the ECM process and due to mathematical difficulties in solving field problems [3]. It is usual practice, therefore, to build an approximate, but sufficiently adequate model of the object, to find a solution for the model, and to refine the solution and model as may be necessary [4]. More specifically, one selects few key factors to describe their effect on the forming process and finally apply whatever corrections may be necessary in order to account for the influences left out of consideration.

Many papers concerning the accuracy in the ECM process have been published [5-8]. Most of these publications have been presented to model and simulate the geometry of the gap size in the ECM process [9-13]. However, hardly, no publications have been submitted about the general models for the shape error of the workpiece pofile in the ECM process. Shape error represents the difference between the maximum and minimum dimension of the workpiece profile after ECM action (Fig. 1). Certainly, this factor could affect the ECM accuracy.

The objectives of this investigation are: 1) develop the theoretical models for the shape error of the workpiece profile in the ECM process; 2) perform computer simulation concerning the shape error of the workpiece; 3) analyze the influence of the process parameters occurring within the machining area on shape error of the workpiece profile; 4) design and carry out the experiments to verify the developed theoretical models. 


\section{Theoretical Models of Shape Error in ECM}

Shape error is the difference between the maximum and minimum dimension of the workpiece profile after the ECM process. Shape error is affected by the non-steady physical phenomena in the gap, such as conjugate fields of the electrolyte flow velocity, static pressures, temperature, gas concentrations, current densities, and metal removal rate distribution on the workpiece surface [4]. The Theoretical models and the analyses based on the models not only give a deeper insight into the ECM gap and anodic processes, but also lay a foundation for the development of the process simulation, computer-aided shape prediction, and tool design [9].

To develop a theoretical model for shape error in ECM, the following assumptions have been made: (a) Ohm's law holds over the entire gap up to the surface of the electrodes; (b) at each electrode, the potential remains the same over the entire surface area and through out the machining time; (c) the angle between feed rate and dissolution a is neglected (Fig. 2); (d) heat transfer through the electrolyte is neglected; (e) the volumetric electrochemical equivalent $K_{v}$ remains constant in both time and space; (f) the pressure in the interelelctrode gap is assumed to be linearly decreasing and dropping to atmospheric pressure at the outlet.

Based on the previous assumptions, the theoretical model of shape error in the ECM process with constant feed rate in the steady state will be defined first. The effect of temperature rise and hydrogen gas bubble on the gap value will be achieved.

\subsection{Shape Error Defination}

The shape error $\Delta B$ is defined as the difference between the maximum and the minimum dimensions of the workpiece profile after ECM action which is equal to the difference between $S_{\max }$ and $S_{\min }$ (Fig. 1 )

$$
\Delta B=S_{\max }-S_{\min }
$$

where $S_{\max }$ and $S_{\min }$ are maximum and minimum gap size respectively. The gap sizes equation can be written in the form of :

$$
S(x)=S_{f}^{0}\left(1+\alpha_{T} \theta\right)(1-\beta)^{\frac{3}{2}}
$$

where:

$\alpha_{T}$ is temperature coefficient of electrolyte conductivity $(1 / \mathrm{K})$,

$\theta$ is temperature increment of the electrolyte in the gap (degree, $\mathrm{K}$ ),

$\beta$ is the volume concentration of gas in the gap,

$S_{f}^{0}$ is the inlet gap size in the steady state. The conductivity can be derived by combining Bruggeman's relation [14] 
$\chi=\chi_{0}\left(1+\alpha_{T} \theta\right)(1-\beta)^{\frac{3}{2}}$

where :

$\chi_{0}$ is the inlet electrolyte conductivity (A/v.mm)

According to Ohm's Law, the current density can be estimated as follows:

where:

$$
i=\chi_{0}\left(1+\alpha_{T} \theta\right)(1-\beta)^{\frac{3}{2}} \cdot \frac{U_{0}-\Delta U}{S}
$$

$U_{0}$ is the voltage (volt), and $\Delta U$ is over potential (volt).

$$
\theta=T-T_{0}
$$

In order to evaluate the maximum and minimum gap size, the temperature and the concentration of gas should be calculated as following
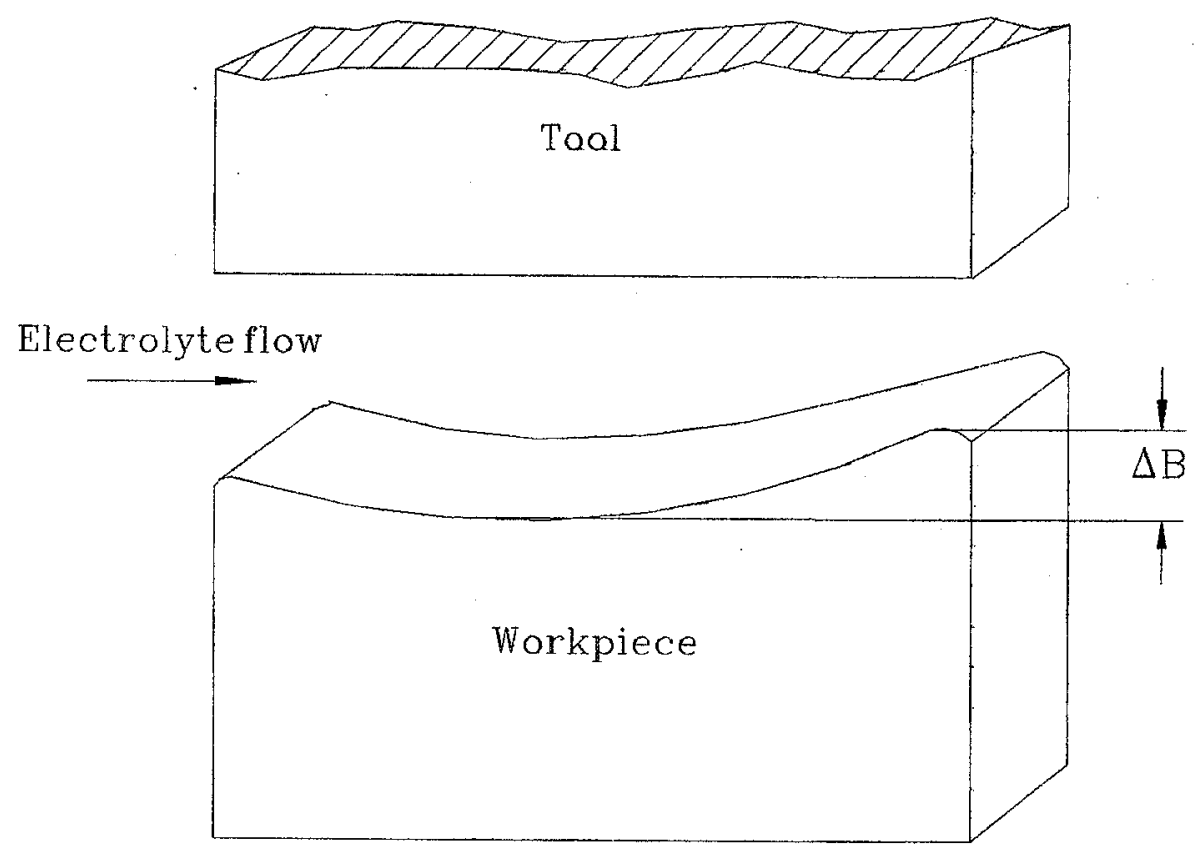

Fig. 1. Shape error in the ECM process

\subsection{Temperature in the Gap}

The increment of temperature in the gap has been derived as follows [10]

$$
\theta=\frac{U_{0} \frac{V_{f}}{K_{u}}}{\rho_{0} S_{0} w_{0} C} X
$$

where : 
$V_{f}$ is the tool feed rate $(\mathrm{mm} / \mathrm{min})$,

$K_{v}$ is the volumetric electrochemical equivalent of the anodic material $\left(\mathrm{mm}^{3} /\right.$ A.min),

$\rho_{0}$ is the density of electrolyte medium $\left(\mathrm{kg} / \mathrm{mm}^{3}\right)$,

$w_{0}$ is the inlet velocity of electrolyte $(\mathrm{m} / \mathrm{sec})$,

$S_{0}$ is the initial gap size ( $\mathrm{mm}$ ), and

$C$ is the heat conductivity $(\mathrm{J} / \mathrm{kg}$.degree),

$X$ is the distance from inlet (mm) (Fig 2).

The flow rate is

$$
Q_{v}=S_{0} w_{0} b
$$

where

B is width of the workpiece. Considering $X=G$, where $G$ is the whole length of workpiece, the maximum increment of temperature can then be expressed as

$$
\theta_{\text {max }}=\frac{U_{0} V_{f} b G}{\rho_{\theta} K_{r} C Q_{v}}
$$

Substituting Eq. (6) into Eq.(5), yields

$$
T=T_{0}+\frac{U_{0} i X}{w_{0} S_{0} \rho_{0} C}
$$

where

$i$ is the current densit $\left(\mathrm{A} / \mathrm{mm}^{2}\right)$

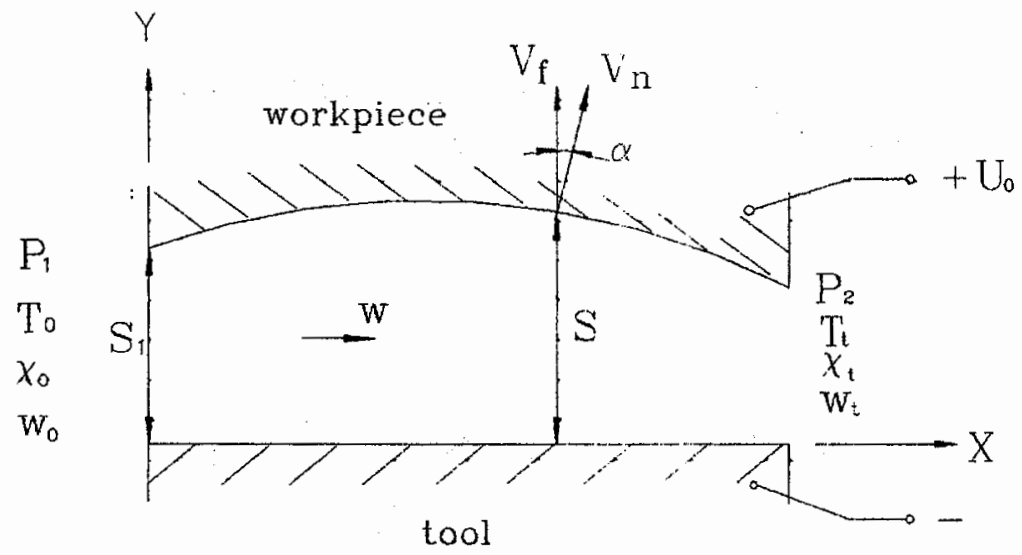

Fig. 2. Schematic diagram showing the relation between feed rate and normal direction of anode 


\subsection{Volumetric Concentration of Gas}

It is clear from Eq. (4), that the gas content affects the current density, and consequently it affects the material removal rate. Analysis of gas content in the gap is very important for the calculation of shape error.

Figure 3 shows how electrolyte temperature and gas content affect the distribution of local metal-removal rates in a plane-parallel gap. The hydrogen evolving at the tool produces a two-phase layer (electrolyte and hydrogen bubbles). Under certain conditions, this layer may fill all of the gap.

The next equation focuses on the calculation of the volumetric concentration of gas which represents the effect of hydrogen on the electrolyte conductivity (Eq. 3). The volumetric concentration of gas is defined as

$$
\beta=\frac{V_{\text {gas }}}{V_{\text {totat }}}
$$

where :

$$
\begin{aligned}
& V_{\text {gas }} \text { is the volume of gas } \\
& V_{\text {total }} \text { is the total volume. }
\end{aligned}
$$

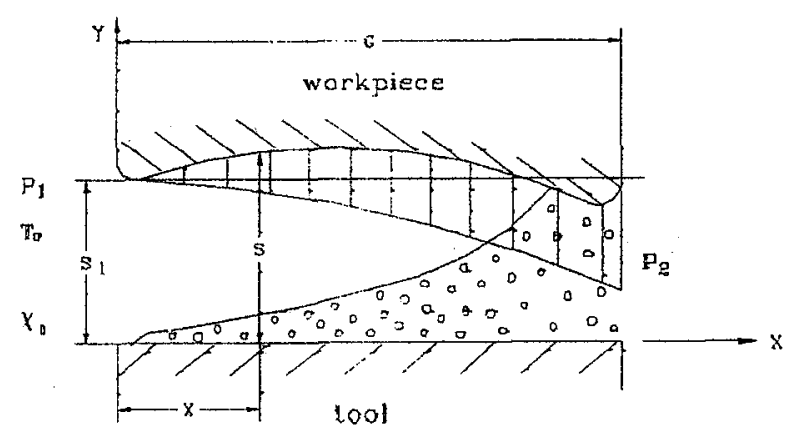

Fig. 3 . Distribution of gas bubbles along the ECM gap After Rumyantsev and Davydov [4]

Total mass in the gap is

$$
m_{t}=\rho_{g} \beta V_{\text {total }}+\left(V_{\text {total }}-V_{g a s}\right) \rho_{a}
$$

where :

$m_{t}$ is the total mass in the gap,

$\rho_{g}$ is the density of gas and

$\rho_{e}$ is the density of electrolyte.

The density of the electrolyte medium can be expressed as [4] 


$$
\rho_{m t}=\frac{m_{m}}{V_{\text {total }}}
$$

where :

$\rho_{m}$ is density of the medium,

$m_{m}$ is the mass of medium and

$V_{\text {total }}$ is the total volume of medium.

It can also be written in the form of

$$
\rho_{m}=\rho_{g} \beta+(1-\beta) \rho_{e}
$$

where :

$\rho_{g}$ is the density of gas,

$\rho_{e}$ is the density of electrolyte and

$\beta$ is the concentration of gas.

Since $\rho_{g} \beta$ is much less than $(1-\beta) \rho_{e}$, one will have

$$
\rho_{m} \cong(1-\beta) \rho_{e}
$$

The mass of the electrolyte medium is conservative, i.e.,

$$
\rho_{0} w_{0} S_{0}=\rho_{m} w S
$$

where

$\rho_{0}$ is the density of the medium at the inlet. Since $\rho_{e}=\rho_{0}$, then

$$
\rho_{0} w_{0} S_{0}=\rho_{0}(1-\beta) w S
$$

The flow velocity can be written as

$$
w=\frac{w_{0} S_{0}}{S(1-\beta)}
$$

By using the pressure relation [16] yields

$$
P_{1}-P_{2}=\lambda \cdot \frac{G}{2 S} \cdot \rho \cdot \frac{\bar{w}^{2}}{2}
$$

By using Blasious formula [16]: $\quad \lambda=\frac{n}{R_{e}^{m}}, \quad R_{e}=\frac{2 S \cdot \bar{w}}{\gamma}$ where :

for turbulent flow

$n=0.316$

$m=0.25$ 
for laminar flow

$$
\begin{aligned}
& \begin{array}{l}
n=96, \\
m=1
\end{array} \\
& R_{e} \text { is Reynolds number, and viscosity }\left(\gamma=\frac{\mu}{\rho} \mathrm{m}^{2} / \mathrm{sec}\right) . \\
& \text { W is the main electrolyte velocity }
\end{aligned}
$$

For turbulent flow, flow velocity can be expressed as

$$
w_{0}=\left[\frac{S_{f}\left(\frac{2 S_{f}}{\gamma}\right)^{0.25} \Delta P}{0.0079 G \rho}\right]^{\frac{1}{1.75}}
$$

where

$\Delta P=P_{1-} P_{2}$ is the pressure difference $(\mathrm{MPa})$; for laminar flow, the flow velocity can be expressed as

$$
w_{0}=\frac{S_{f}^{2} \Delta P}{12 G \rho \gamma}
$$

where

$S_{f}$ is the stationary gap size

According to Faraday's Law, the mass of electrolyte medium is

where

$$
m=K I t
$$

$K$ is the current efficiency,

$I$ is current (A) and

$t$ is time (sec).

Referring Eq.(21) the mass volume of the gas $m_{H 2}$ can be written as

$$
m_{H 2}=K_{H 2} i b \cdot d x \cdot d t
$$

where

$b$ is the width of the gap ( $\mathrm{mm})$,

$i$ is the current density $(\mathrm{A} / \mathrm{mm} 2)$.

Therefore, the mass of the gas is

$$
m_{H 2}=K_{H 2} b \int_{0}^{x} i \cdot d x \cdot d t
$$

i.e.,

$$
m_{H 2}=K_{H 2} b i X d t
$$

The mass of gas can also be presented as 
where

$$
m_{H 2}=\rho_{H 2} \beta w S b d t
$$

$S$ is the gap size,Equaling Eq.(24) and Eq.(25), we get

$$
K_{H 2} i X=\rho_{H 2} \beta w S .
$$

Substituting Eq.(18) into Eq.(26), we get

$$
\beta=\frac{K_{v H 2} \cdot \frac{i X}{w_{\theta} S_{0}}}{1+K_{v H 2} \cdot \frac{i X}{w_{0} S_{0}}}
$$

where :

$K_{v H 2}$ is the volume of the hydrogen generated per ampere of current per second of time $\left(\mathrm{m}^{3} / \mathrm{A} \cdot \mathrm{sec}\right)$, it can be defined as

$$
K_{v H z}=\frac{K_{H 2}}{\rho_{H 2}}
$$

where

$K_{H 2}$ is the coefficient of gas,

$\rho_{H 2}$ is density of gas.

For perfect gas by referring to Acharya et al. [17], we have

$$
P V=\frac{m_{H 2}}{\mu} R_{\mu} T \text {, }
$$

where

$P$ is the pressure

$$
P(x)=P_{1}-\frac{P_{1}-P_{2}}{G} X
$$

where

$V$ is the volume,

$T$ is the temperature,

$m_{H 2}$ is the ass of gas in the volume,

$R_{\mu}$ is the gas constant and

$\mu$ is the weight of atom mass. Eq.(27) can also be written as

$$
\begin{aligned}
& \frac{P}{\rho_{g}}=\frac{R_{\mu}}{\mu} T \\
& \frac{P_{n}}{\rho_{n}}=\frac{R_{\mu}}{\mu} T_{n}
\end{aligned}
$$


where

$$
\begin{aligned}
& \rho_{g}=\frac{m}{V}, \\
& P_{n} \text { is the normal pressure, } \\
& T_{n} \text { is the normal temperature. }
\end{aligned}
$$

Dividing Eq.(31) by Eq.(29), yields

$$
\rho_{g}=\rho_{n} \frac{P T_{n}}{P_{n} T}
$$

Multiplying Eq.(32) by $K_{H 2}$ on both sides, comes out

$$
K_{v H 2}=\frac{K_{H 2}}{\rho_{n}} \cdot \frac{P_{n}}{P} \cdot \frac{T}{T_{n}}
$$

Substituting Eq.(33) into Eq.(27), yields

$$
\beta=\frac{\frac{K_{H 2}}{\rho_{n}} \cdot \frac{P_{n}}{P} \cdot \frac{T}{F_{n}} \cdot \frac{i X}{w_{0} S_{0}}}{1+\frac{K_{H Z}}{\rho_{n}} \cdot \frac{P_{n}}{P} \cdot \frac{T}{T_{n}} \cdot \frac{i X}{w_{0} S_{0}}},
$$

where

$$
\begin{aligned}
& i=\frac{V_{f}}{K_{v}}, \frac{K_{H 2}}{\rho_{n}}=1.25 \times 10^{-7}\left(\mathrm{~m}^{3} / \mathrm{A} \cdot \mathrm{sec}\right) \\
& P_{n}=10^{5}\left(\mathrm{~N} / \mathrm{m}^{2}\right) \text { and } \\
& T_{n}=273^{\circ} \mathrm{k} .
\end{aligned}
$$

Eq. (33) can then be written as

$$
K_{v H 2}=\varepsilon_{H} 1.25 \times 10^{-7} \cdot \frac{10^{5}}{P} \cdot \frac{T}{273}
$$

where

$$
\begin{aligned}
& \varepsilon_{H} \text { is the efficiency of gas, } \\
& \varepsilon_{H}=1 \text { for } \mathrm{NaCl}, \\
& \varepsilon_{H}=0.6 \text { for } \mathrm{NaNO} 3[10] .
\end{aligned}
$$




\section{Computer Simulation of the Shape Error}

In order to analyze the shape error of the workpiece in the ECM process and to predict it, the computer simulation has been performed by using the theoretical models developed in the previous section. The parameters used in the simulation of the shape error are collected from experimental results and listed in Table 1 for stationary and feed rate cases.

Table 1 The parameters used in the simulation of the shape error

\begin{tabular}{|c|c|c|c|c|c|}
\hline No & Parameter & Symbol & Value & Unit & Comments \\
\hline 1 & $\begin{array}{c}\text { Over } \\
\text { potential }\end{array}$ & $\Delta U$ & 2 & volt & $\operatorname{Ref}[8]$ \\
\hline 2 & $\begin{array}{l}\text { Density of } \\
\text { electrolyte }\end{array}$ & $\rho$ & 1120 & $\mathrm{~kg} / \mathrm{m}^{3}$ & Experimental \\
\hline 3 & $\begin{array}{l}\text { Viscosity of } \\
\text { etectrotyte }\end{array}$ & $\gamma$ & $10^{-6}$ & $\mathrm{~m}^{2} / \mathrm{sec}$ & $\operatorname{Ref}[111]$ \\
\hline 4 & $\begin{array}{l}\text { Electrolyte } \\
\text { conductivity } \\
\text { in the inlet }\end{array}$ & $\chi_{0}$ & $0.01 \mathrm{IT}$ & $\mathrm{A} / \mathrm{v} \cdot \mathrm{mm}$ & Experimental \\
\hline 5 & $\begin{array}{l}\text { Volumetric } \\
\text { electrochemi } \\
\text { cal } \\
\text { equivalent }\end{array}$ & $K_{v}$ & 1.9 & $\mathrm{~mm}^{3} / A \cdot \min$ & Experimental \\
\hline 6 & $\begin{array}{c}\text { Inlet } \\
\text { temperature }\end{array}$ & $F_{0}$ & $293 \mathrm{k}\left(20^{\circ} \mathrm{C}\right)$ & degree & Ref.[11] \\
\hline 7 & $\begin{array}{c}\text { Critical } \\
\text { Reynolds } \\
\text { number }\end{array}$ & $R_{\varepsilon}$ & 2400 & & Ref.[16] \\
\hline 8 & $\begin{array}{c}\text { Heat } \\
\text { conductivity } \\
\text { of electrolyte }\end{array}$ & $C$ & 3700 & $\mathrm{~J} / \mathrm{kg} \cdot \mathrm{deg}$ & Ref.[II] \\
\hline 9 & $\begin{array}{c}\text { Temperature } \\
\text { coefficient }\end{array}$ & $\alpha_{T}$ & $\theta .02$ & t/deg. & Ref: $[11\}$ \\
\hline
\end{tabular}

\section{Experimental Verification}

The experiments were performed on an ECM cell, which consists of an electrolyte holding tank, a pump, power supply and appropriate hosing and pressure fittings to transport the electrolyte to and from the electrochemical cell (Fig. 4). Measurements have been used to conduct the electrochemical accuracy experiments included an IBM compatible $386 / 25 \mathrm{MHz}$ PC, conductivity and temperature probe meters (Orion, model 160 ), a precision laboratory scale (Sartorius, E-1200S) with a readability of $0.1 \mathrm{mg}$, and a state-of -the-art high speed data acquisition package (ISO-16) to collect data from the ECM cell. A 
Brown \& Sharp Microval Coordinate Measuring Machine (CMM) was used to measure the dimensions of workpiece after and before the ECM process.

The constructed ECM machining cell, consists of a cathode (tool) and an anode (workpiece) kept at a constant gap from each other by controlling the height of the tool with an accuracy of $0.01 \mathrm{~mm}$ through CMM equipment. The cell was designed to withstand a high electrolyte pressure. The constructed cell was made from stainless steel 304 and Teflon to avoid the corrosion and to reduce the tool and the workpiece fixture wear. Tool and workpiece holders were made from 304 stainless steel . The machined specimen is of a rectangular shape ( height $A=22.86 \mathrm{~mm}$, width $b=3.073 \mathrm{~mm}$, length $G=40 \mathrm{~mm}$ and surface area of $122.8 \mathrm{~mm}^{2}$. The specimens were made of ground die steel (Badger 01) produced in U.S.A.(0.94\% Carbon, 0.3\% Silicon, $1.2 \%$ Manganese, $0.5 \%$ Tungsten, $0.5 \%$ Chromium). The electrolytes used in these experiments were $15 \% \mathrm{NaNO} 3$ and $15 \% \mathrm{NaCl}$ aqueous solutions (by weight) maintained at initial temperature of $20^{\circ} \mathrm{C}$. To overcome the problem of temperature rise during the $\mathrm{ECM}$ process a large quantity of electrolyte was pumped through the working gap to minimize the temperature rise. The experiments have been done under stationary tool feed rate conditions.

The experimental set-up includes a precision engineered transistorized power supply. The generator is capable of supplying maximum currents of 200 amperes, a voltage ranging from 5 to 30 volts with $0.5 \%$ RMS. ripple. This is controlled by a Siemens power relay which in turn is controlled by a Gralab 645 Digital timer for accurate machining time and easy control. Accurate machining timer was needed for calculating the material removal rates precisely.

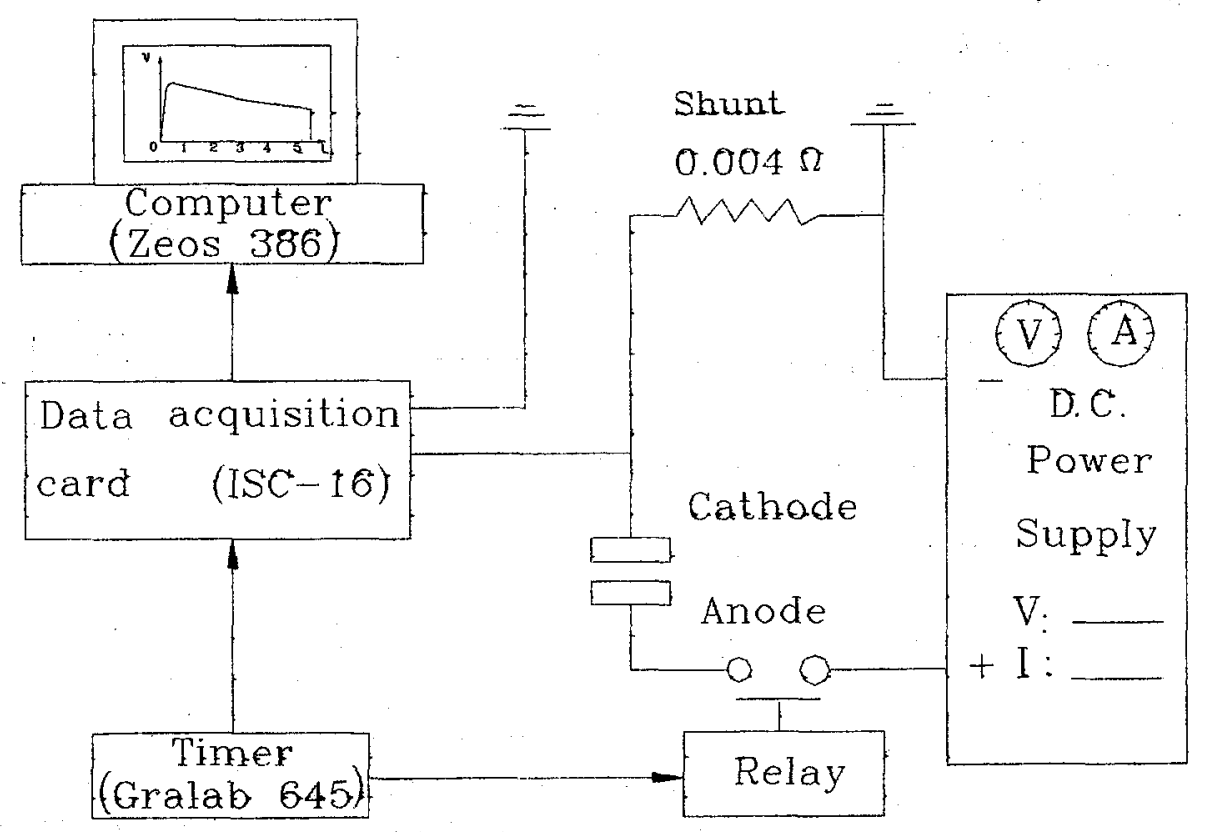

Fig. 4 Schematic diagram of the data acquisition system for the ECM cell. 
Electrolyte temperature, inlet pressure, electrolyte flow rate and gas content are the main factors which affect the distribution of local metal-removal rates in a plane-parallel gap. The present results have been collected from 228 measurements carried out on the stationary conditions. Experimental results are shown in Figs. 5-9 as dashed lines. Each point comes from 3 experiments and each point has been measured 4 times and then the average was computed. The solid lines are the calculations of the mathematical models. It is shown that the calculation of the results are quite promising with the experimental results. The theoretical models can, therefore, be used to simulate and predict the shape error.

Figures. 5n 6 show that shape error $\Delta B$ decreases as the machining time (t) increases, for $\mathrm{NaCl}$ (Fig. 5), and NaNO3 (Fig. 6) electrolyte. This result has been attributed to the decrease of the metal removal rate at the wide gap values which consequently decreases the variation difference in the resultant metal removal . Figure 7 shows that as voltage increases $\Delta B$ increases. This result is due to the increase of the variation of the metal removal rate at the high curent density values. Figure 8 shows that as initial gap length increases $\Delta B$ decreases because of the decrease of the metal removal rate. Figure 9 shows the limited effect of the electrolyte pressure on the decrease of the shape error value. Figs. $10-13$ show the shape profile of the workpiece after machining under different machining times. Shape profile has been drawn through 10 points, each point has been measured 5 times and then computed the average. It is seen that the effect of the increase of temperature leads to increase of the metal removal during all the first half portion from the inlet. However, after certain machining time, the effect of gas concentration became pronounced and led to less metal removal as the flow progress. This is the reason for the concavity of the workpiece profile. For 57 experiments have been conducted the maximum shape error in the present work was $36 \mu \mathrm{m}$. "The maximum variation between theoretical and experimental results was about $10 \mu \mathrm{m}$ which consequently emphasizes the analysis and the computer simulation.

\section{Conclusions}

- Experimental results proved that shape error is a vital factor in the accuracy of the ECM process. It should be considered during the analysis of the ECM accuracy ( $\Delta B$ is about. $04 \mathrm{~mm}$ along $40 \mathrm{~mm}$ workpiece length).

- Theoretical analysis and experimental results were confined with each other with a variation usually less than $0.01 \mathrm{~mm}$, which emphasizes the adequacy of the suggested model.

- The shape error factor could be extended for further applications with complex shapes as an endeavour towards the enhancement of the ECM accuracy. 


\section{References}

[1] Wilson, J. F., Practice and Theory of Electrochemical Machining, WileyInterscience, 1971.

[2] McGeough, J. A Advanced Methods of Machining, Chapman and Hall, London, 1988.

[3] McGeough, J. A, Principles of Electrochemical Machining, Chapman and Hall, London, 1974.

[4] Rumyantsev, E. and Davydov, A, Electrochemical Machining of Metals, MIR Publishers Moscow, 1989.

[5] Kozak, J., Dabrowsi, L., Lubkowski, K., and Peronczyk, J., "Geometry of Electrodes in the Electrochemical Machining," Proc. of the 7 th ISEMSymposium, Birmingham, England, 1983, pp.454-467.

[6]. Kozak, J., Abdel Mahboud, A. M. and Lubkowski, K., " Enhance the Accuracy of Electrochemical Machining Process," Proc. of the the 3rd. ASAT Conf., MTC , Cairo, Egypt.PT-9, pp 715-731, April, 1989

[7] Rajurkar, K. P. and Wei, B., "Monitoring and Control of Electrochemical Machining (ECM)," Transactions of the ASME, J of Engg. for Industry, Vol. 115, May 1993, pp. 216-223.

[8] Hives, J. and Rousar, I., "Measurement of Anode Potentials at High Current Densities by the Current Interruption Method for Metals Used in Aviation Technology," J of Applied Electrochemistry, No. 23, 1993, pp. 1263-1267.

[9] Kozak, J., Dabrowski, L., Rozenek, M, Rajurkar, K. P. and Slawinski, R. J.,"Computer-Aided Tool Design for the Electrochemical Machining of Axially Symmetric Workpieces," Manuf. Science and Engg., Vol.1, 1994, pp. 317-324.

[10] Kozak, J. and Lubkowski, K., "Computation of Physical Conditions and Geometry of the Gap in the Steady State of Electrochemical Machining," Proc. of the27 th Int. MATADOR Conf. , Manchesţer, England, April, 1988, pp. 269-274.

[11] Kozak, J., Davrowski, L., Lubowski, K, and Rozenek, M., "Computer Aided Electrochemical Machining," Proc. of the 10 th Int. ISEM. Symposium on Electromachining, CIRP,Magdeburg Germany, May 1992, pp. 446-475.

[12] Kozak, J. and Rajurkar, K. P., and Wei, B., "Modeling and Analysis of Pulse Electrochemical Machining (PECM)," Transaction of the ASME, J of Engg. for Industry, Vol. 116, August, 1994, pp. 316-323.

[13] Kozak, J., Dabrowski, L. and Rozenek, M.,"CAD of Tool Electrodes for ECM and Simulation of Anode Shape Evaluation by Means of Micro Computer," Proc. of the 9 th Int. ISEM Symposium, Japan, 1989, pp. 139-142.

[14] Bruggeman, A. G. Ann., "Physis", Vol. 24, n7., 1935, pp. 636-664.

[15] D. VAN NOSTRAND COMPANY, INC., "The Int.Dictionary of Applied Mathematics", New Jersey,usA 1967, pp. 683. 
[16] John, J. E. A., and Haberman, W. L., "Introduction to Fluid Mechanics", Prentice-Hall, Inc., Enlewood Cliffs, New Jersey, USA, 1980.

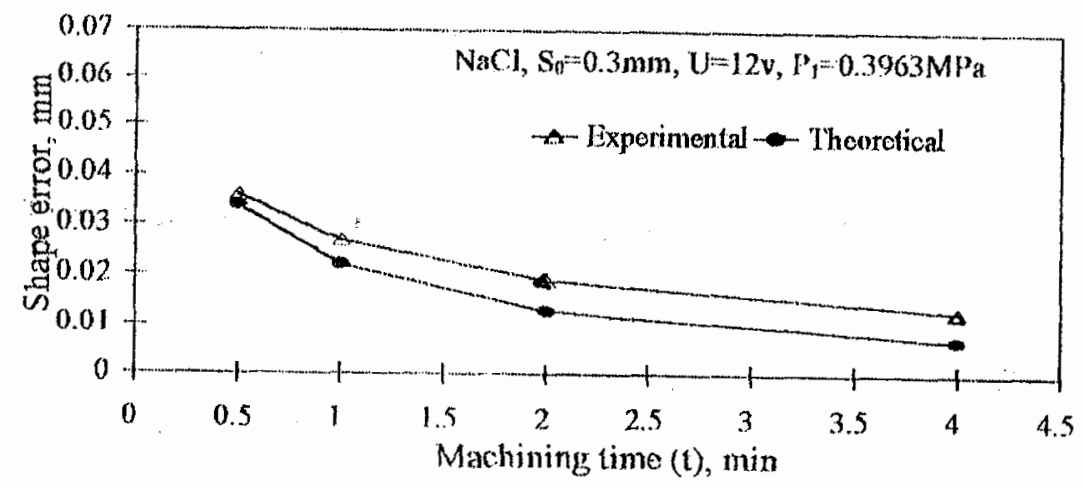

Jig. 5 liffect of machining time on shape error with $\mathrm{NaCl}$

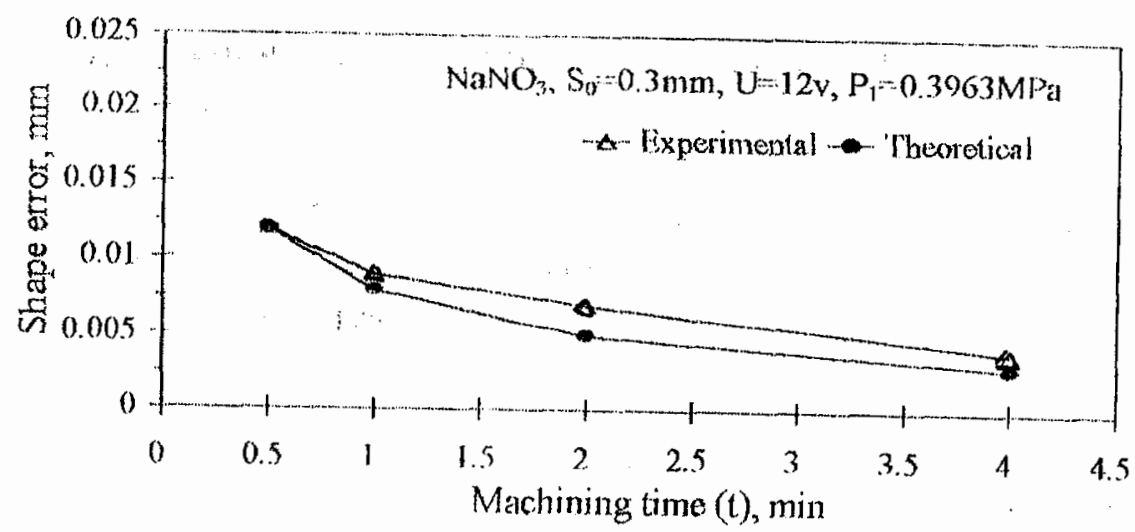

lïg. 6 liffect of machining time on shape error with $\mathrm{NaNO}_{3}$ 


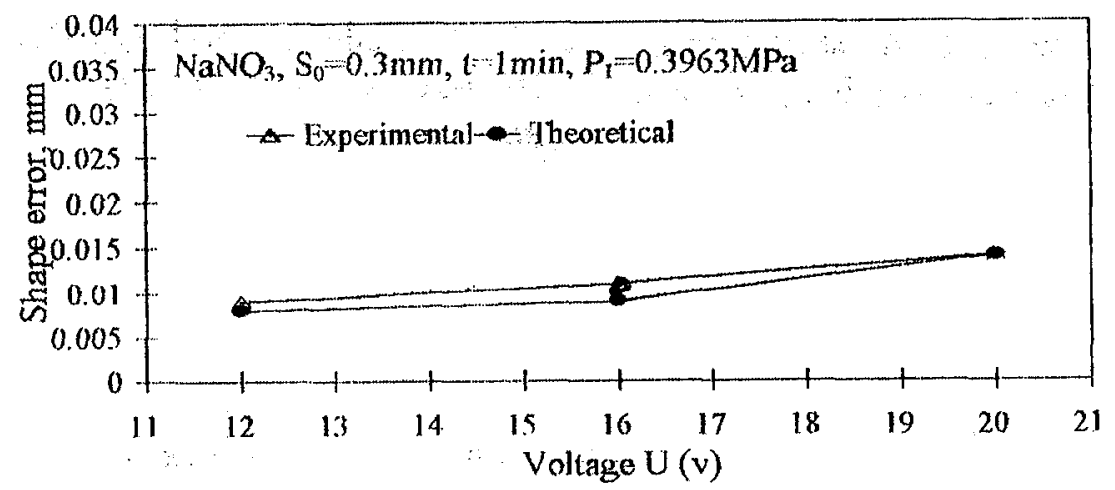

lig. 7 Efrect of the applied voltage on shape error

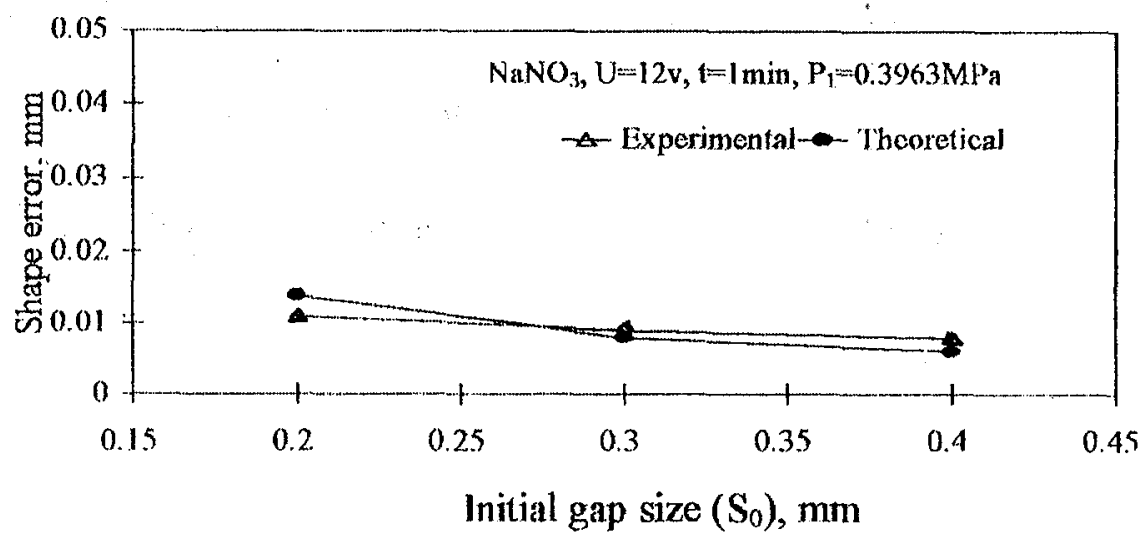

Iig. 8 liffect of the initial gap size on shape error

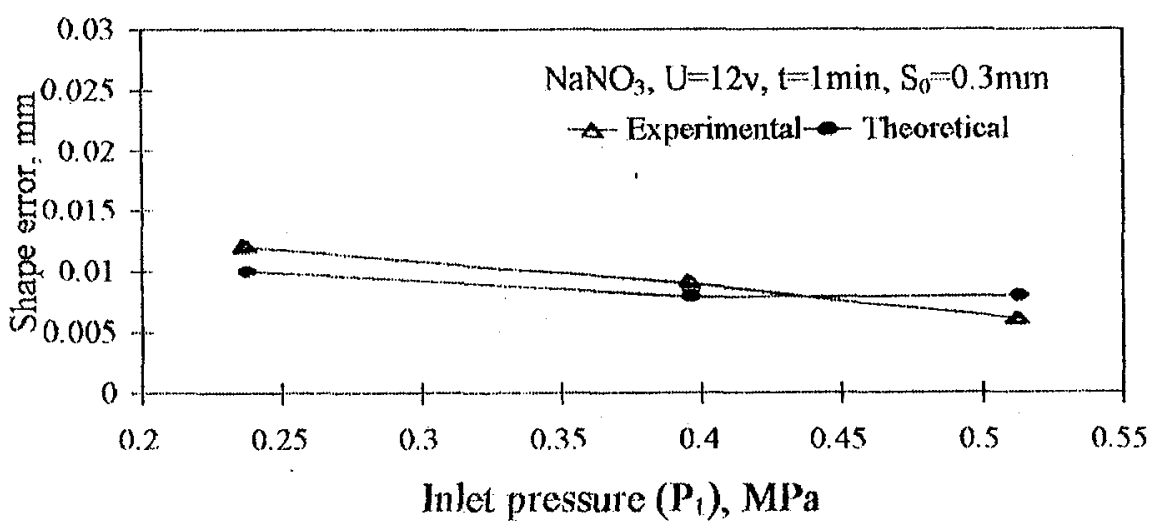

lig. 9 Effect of the inlet pressure on shape error 


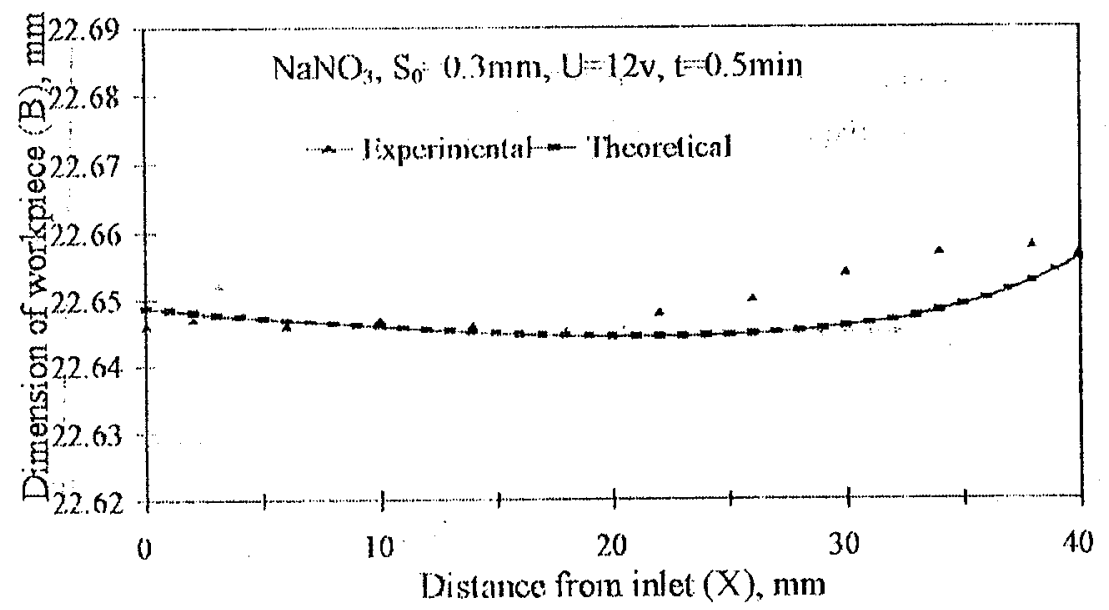

lig. 10 Shape of work piece after machining

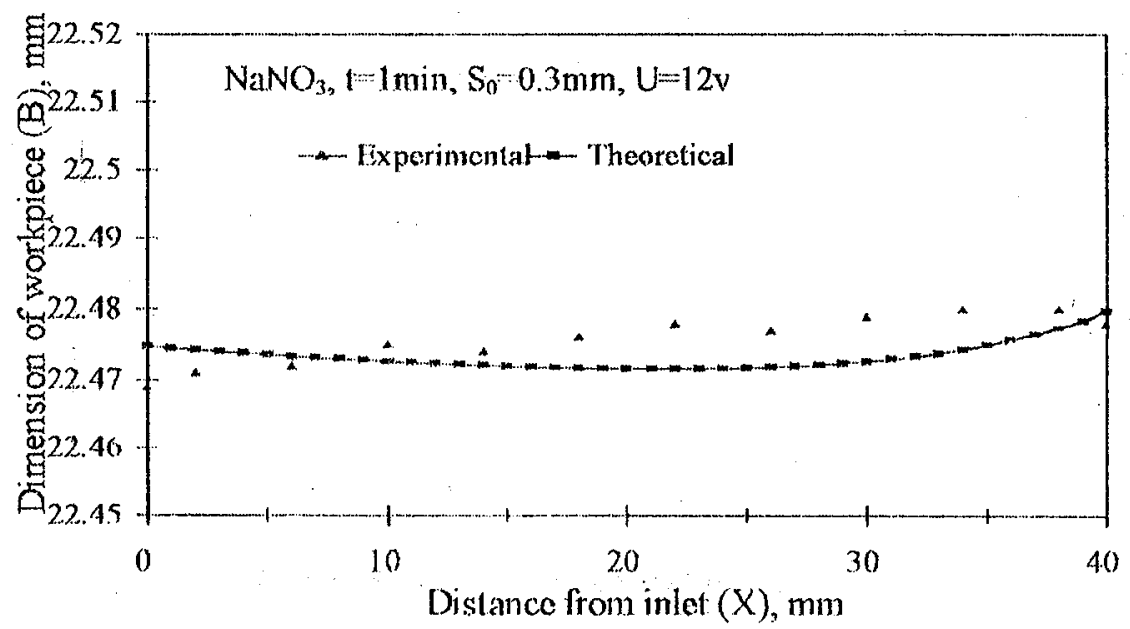

Fig. /1 Shape of workpiece after machining 


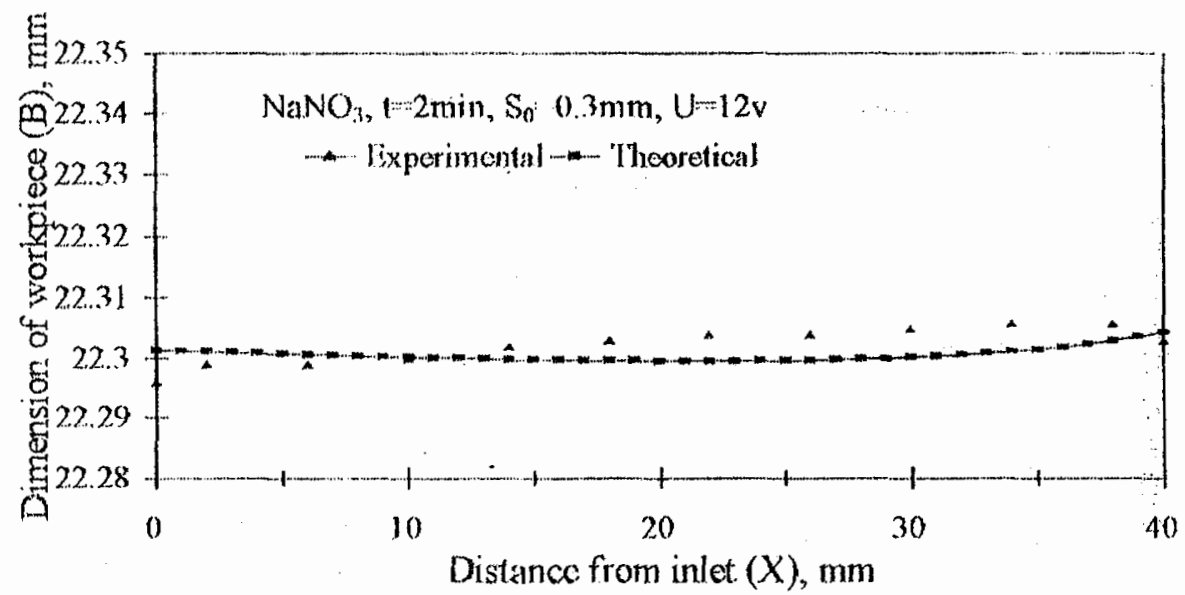

liig. 12. Shape of workpiece after machining

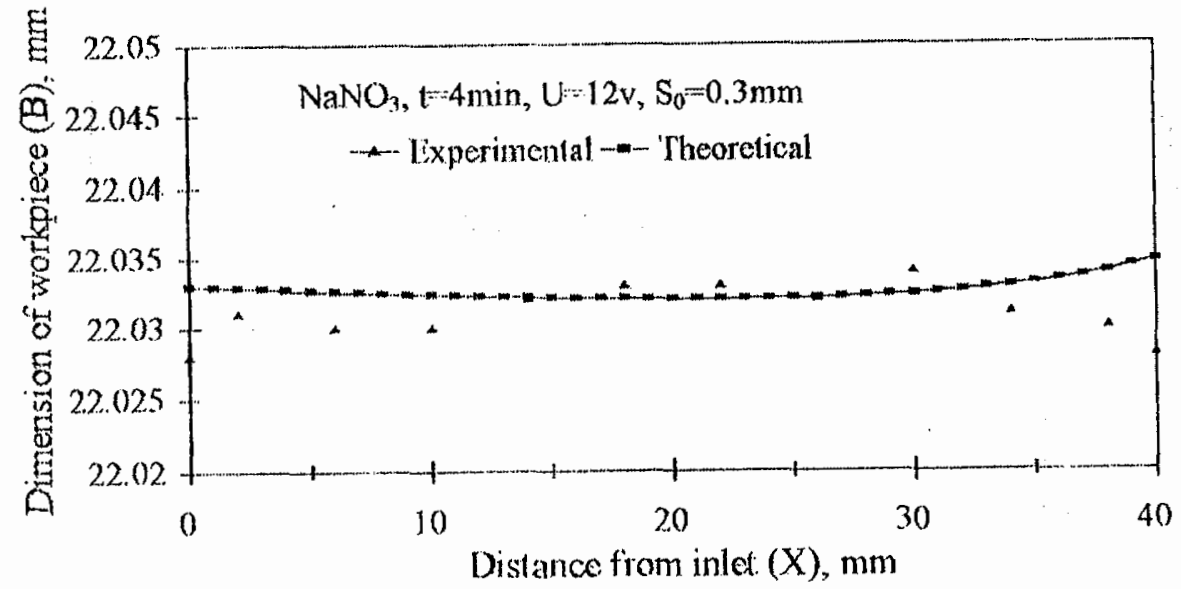

lig. 13 Shape of workpiece after machining 


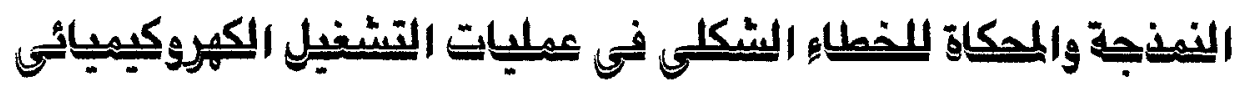

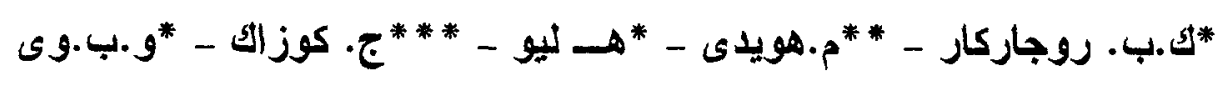

*مركز ابحاث التشغيل الغير ثقلبدى جامعة نبراسكا ( الو لايات المتحدة الامريكية ) * استاذ مساعد زائر من جامعة المنوفية ( جمهورية مصر العرببة ) * استاذ زائر من جامعة وارسو ( بولندا )

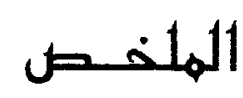

يتتاول البحث جانبا من جو انب الدقة لعمليــات النتــغيل الكــهروكيميائى والمســـى

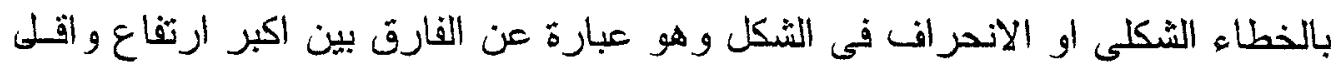

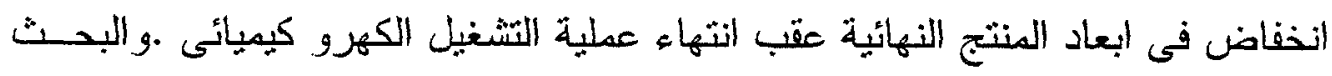

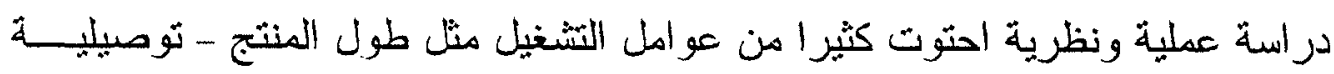

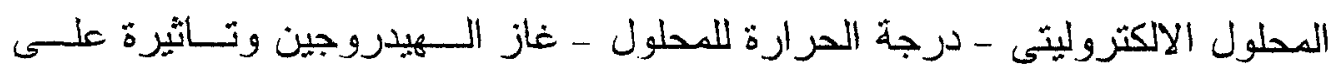

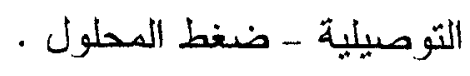

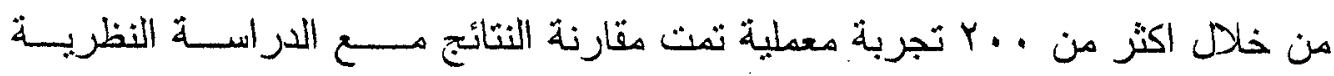

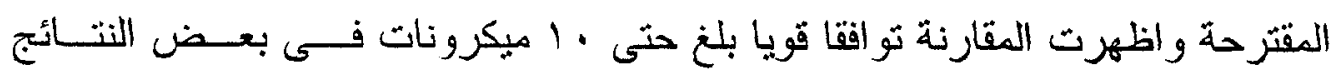

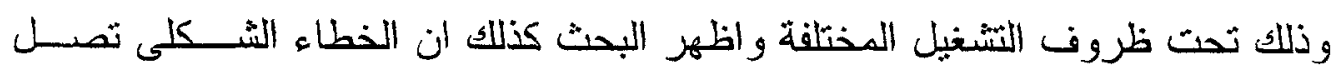

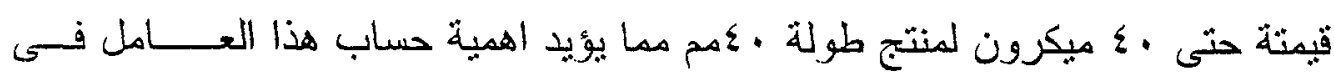

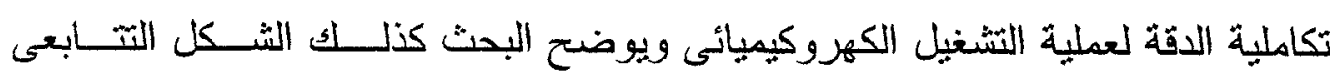

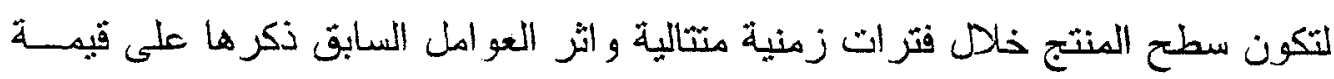
· الاتحر افت الشكلى سطع 